\title{
Adding Lemon Juice to Poison - Raising critical questions about the oxymoronic nature of mindfulness in education and its future direction.
}

By Edward M. Sellman* \& Gabriella F. Buttarazzi**

*Centre for Research in Human Flourishing, University of Nottingham, UK

$* *$ University of Nottingham Ningbo, China

\begin{abstract}
This article seeks to amplify a debate initiated in this journal by Hyland (2016) by deepening a number of conceptual, methodological and implementational issues concerning the application of mindfulness based interventions (MBIs) to schools and other places of learning. It argues that the pursuit of the byproducts of mindfulness, enhanced focus and well-being, serve a neoliberal agenda for education. This is lemon-juice to poison as it encourages students to accept and cope with oppressive structures partially responsible for suffering in society rather than develop the deepened awareness necessary to challenge and transform them. Reconnecting mindfulness with its original meaning of remembrance and discernment is highlighted as a means for engaging students with more agentic possibilities. The article begins to make the case for mindfulness as education, rather than mindfulness in education, realised as an embodied approach rather than psychological intervention with key roles for contemplative pedagogy and mindful inter-personal relationships.
\end{abstract}

\section{Key words: mindfulness-based interventions, neoliberalism, schooling, contemplative pedagogy, discipline}

\section{Introduction}

There has been an exponential surge in interest in mindfulness-based interventions (MBIs) applied to educational institutions, accompanied by a growing multi-disciplinary evidence-base (Weare 2012, Zenner et al 2014). 
Whilst reported benefits in concentration and well-being are welcome, there is also concern that mindfulness is being conceptually diluted to help people cope with the structures and lifestyles associated with neoliberalism rather than contest their impact through deepened awareness (Farias \& Wikholm 2015, Reveley 2016). This article seeks to respond to and extend a debate initiated in this journal by Hyland (2016) by deepening a number of conceptual, methodological and implementational issues. It shares much common ground but seeks to ratchet the debate further by problematising the oft taken-forgranted functionality of schooling and its relationship to mindfulness. It will argue that it is necessary to rigorously examine definitions of mindfulness applied to educational settings.

As a way of beginning to identify possible future direction, the article will support the call for a more contemplative pedagogy, so that mindfulness is positioned as a means for personal and social transformation rather than cultural reproduction. It will conclude with the argument that mindfulness needs to be reframed as a collective way of being within a humanistic model of schooling (mindfulness as education) centred on first-person experience, deep self-knowledge, ethics and agency rather than an individual way of coping with current oppressive models of education (mindfulness in education). Such theorisation draws upon a number of writers, most notably Ergas $(2015,2017,2018 a)$ who has recently (Ergas 2018b) also began to articulate similar distinctions between modalities of mindfulness in education, though the notion of mindfulness as education to be introduced here advocates a possibly deeper and more critical sensibility. The article will begin to identify what mindfulness as education could look like, though a full expose is beyond the scope of this particular piece of writing. Mindfulness as education will certainly warrant a deep scrutiny of organisation and pedagogic practice and the article will recommend specific attention to discipline and inter-personal relationships being a good starting-point. Ultimately, mindfulness in schools needs to be seen as an educational initiative in its own right rather than a psychological intervention.

\section{Mindfulness in Education}




\section{The journey from spirituality to health intervention to education}

Mindfulness has clear philosophical/spiritual origins. Briefly, the term refers to a process identified by the Buddha that it is not necessarily our apparent physical reality that causes suffering but how we relate to it. The approach was attractive to Kabat-Zinn (2013a, 2013b), who considered a secular form of mindfulness as an acceptable and potentially helpful form of stress-reduction for his hospital patients in the US with serious illnesses for whom traditional medicine could offer little respite. Segal et al (2013), influenced by Kabat-Zinn's initial success also adapted the approach as a form of cognitive-therapy for those experiencing depression in the UK. These programmes were so well-received that they have been adapted for various other institutional contexts with reported benefits for even brief practice on focusing abilities and perceived well-being (Chaskalson \& Reitz 2018).

Subsequently, there has been unilateral political interest in mindfulness in many countries. Both ends of the political spectrum encourage further research and implementation in educational and health settings (NEF 2014). Mindfulness appears to be popular with the left/liberal wing as it is seen as a form of empowering individuals and equally popular with the right/conservative wing as a means of reducing the burden on state resources and building individual resilience and efficiency (Safran 2014). Educational policy has also largely welcomed the potential of mindfulness for addressing aspects of learning and well-being (Weare 2012). Whilst attractive to the objectives of neoliberalism it is also viewed as popular with many educators as a means of offsetting precisely the same agenda through concession to affective education marginalised by three decades of incessant performativity, a narrower curriculum and emphasis on crude outcome measures all impacting on pupil and teacher stress (Hyland 2014). Exactly how mindfulness relates to these agendas warrants scrutiny and will be a theme throughout the remainder of this article.

Weare (2012) provides a systematic literature-review of the evidence underpinning mindfulness in schools. It concludes that a significant body of evidence exists, appearing to validate the success of programmes in schools. It 
is no wonder that mindfulness as an intervention is so attractive to policymakers wanting to milk yet higher standards out of teachers and students. NEF (2014) and Weare (2012) advocate larger and longitudinal research projects without asking fundamental questions about the nature and purpose of education itself. The Oxford Mindfulness Research Centre's Myriad project has since secured funding for a large randomised-controlled-trial (RCT). It will look at the impact of the '. $b^{\prime}$ curriculum for students aged 11-14 offered by the UK Mindfulness in Schools Project (MiSP) and its counterpart, 'paws.b' for younger children (7-11). Large RCTs have a place but this article will argue that such an approach is misguided in focus and methodology. We will argue that such research positions mindfulness as a psychological intervention to help young-people cope with the educational system rather than asking timely and significant questions about the nature of education itself and how mindfulness may catalyse a contemplative turn in education (Ergas 2018a) that privileges deeper personal inquiry, holistic development and an empowered orientation to the world. Before we engage with such issues in greater depth let's first examine why an instrumental focus is defendable but ultimately, limited.

\section{Why an instrumental focus may be defendable}

There has been an undeniable interest in applying mindfulness in multiple contexts. Articles about mindfulness have grown from single figures in the $1980 \mathrm{~s}$ to over 400 per year since 2011 (American Mindfulness Research Association 2017). The number of articles specifically about mindfulness in education shows a similar but shallower trend with over 150 journal articles in 2014, 30 of which were peer reviewed (Schonert-Reichl et. al 2016). This interest in mindfulness has undoubtedly been accelerated by concern about mental-health. The Health and Safety Executive (2017) report that $40 \%$ of work-related illness and $49 \%$ of staff absenteeism is linked to stress, with education being singled-out as one of the most vulnerable professions. It has also been reported that $75 \%$ of mental-health difficulties now commence before 24 years of age ( $\mathrm{DOH}$ 2011). Such data underline that mental-health is no longer an adult preoccupation but an acute educational concern. Good evidence exists that mindfulness practices can help 
participants relate to their thinking differently (Siegel 2018), so the initial case for mindfulness as a mental-health intervention has both rationale and merit.

So, what is the objective of mindfulness in education? Is it a clandestine healthintervention or does it have its own educational worth? Peacock (2014) has defended the application of mindfulness as being somehow 'watered-down' and secularised. Kabat-Zinn (2017) defends this process as both a necessary and beneficial consequence of universalising Buddhist sensibilities (spreading 'Dharma') to help those suffering from poor physical and/or mental-health who would not normally consider attending a meditation course. As Buddhism can be positioned as a philosophy or pragmatic approach to life, rooted in first-person experience and observation, it matters more that suffering is reduced than a participant develops a 'religious' identity. Indeed, credit must be given to these endeavours because there is ample evidence that suffering has been reduced for many through meditation practice (Chaskalson \& Reitz 2018, Kabat-Zinn 2013b, 2017, Siegel 2018) and the fact that we are debating mindfulness in health and education settings is testimony to how much has been achieved and how mainstreamed these approaches have become. However, universalisation should not be at the expense of potential scope and depth. Hence, it is worth asking what is lost by overlooking historical, philosophical and etymological roots? As this article progresses, we will suggest - quite a lot.

Informed scholars tend to praise the design of mindfulness-based stressreduction and cognitive-therapy courses as preserving much of the integrity of the teachings from which these approaches originate (Roeser 2014). However, there have also been many that have criticised the universalisation of mindfulness as moving too far away from its original emphasis on deep selfawareness, ethics and civic action (e.g. Hyland 2016) to meet the instrumental goals of improved health and well-being. Any helpful intervention is welcome with those who are really suffering and few could argue that those with serious illness are not suffering more than most. Yet, as mindfulness has become mainstreamed, course-developers have not returned to the original teachings but to these mindfulness-based health interventions when applying them to other contexts. This means important emphases are overlooked when the course has a broader objective. Within education, we need to ask is mindfulness an 
intervention to help students cope with their school or a more ambitious vehicle for human flourishing?

One argument made in this article is that reductionism and commodification, sometimes called 'McMindfulness' (Safran 2014), whilst understandable and necessary to a degree within a medical-model, has over-emphasised by-proxy foci such as stress-management, concentration and happiness to such a degree that it is politically non-threatening when applied to a context such as education. We argue that although the universalisation of mindfulness is welcome it needs to retain its original emphasises on spiritual connection and ethical behaviour in order to be synergistic with education's broader remit for eudemonia/human flourishing as opposed to the instrumental focus present in health settings on alleviating or managing symptoms. Without this re-emphasis, it is like adding lemon juice to poison because mindfulness becomes subservient to the hidden functions of education, chiefly class reproduction and dependency on societal structures, often referred to as the key characteristics of a 'sleeping' consciousness (Taylor 2010). Mindfulness can be a stimulant for a more 'wakeful' consciousness, therefore it is imperative that people's experience permits depth and authenticity, issues discussed in the next section.

\section{Instrumentality as collusion with systemic violence and suffering}

The instrumental application of mindfulness makes young-people the subject of mental-health interventions, which is dangerous because it creates metanarratives locating individuals rather than social-structures as the site of blame (Reveley 2016). There is of course much about suffering that is created by the mind, rather than our external conditions and mindfulness is a powerful vehicle for deconditioning and developing attributes such as acceptance. However, we need to guard against one-sidedness as this could result in acceptance of the very structures that oppress us. Instrumentality should not be belittled, mindfulness without ethics can have dark applications, such as within the military or globalised industries (Farias and Wikholm 2015). Doty (2016) has shown how mindfulness may result in high-performance but without compassion, also depression. Mindfulness can help reduce suffering in those situations that 
are genuinely difficult to change but when applied superficially it can also be paradoxical as it over-focuses on how we relate to suffering rather than the sources of suffering. Mindfulness used for therapeutic interventions can be problematic and ineffective long-term as participants can chase the by-products (reduced stress, greater focus) without addressing underlying causes and context, further compounded if mindfulness is constructed as 'staying calm' and centred around individual ability. Something disguised as empowering is thus a further source of oppression. Mindfulness accompanied by deeper inquiry however challenges us to review the causes of suffering and what a more connected sense of self requires of us (Ergas 2017, Zajonc 2008).

Hyland (2016) refers to superficial mindfulness as an example of 'spiritual bypassing' (see also Masters 2010), whereby the serious and protracted nature of spiritual practice or deep inquiry is truncated in an attempt to reach positive outcomes. Such processes can be exacerbated when mindfulness is promoted as a product to alleviate various symptoms or improve performance. The causes of much suffering that young-people may need to address are generally not of their own-making but inherited from the adult-world. The current outlook for students in many western education systems is bleak. The economy, itself a fiction that awareness unveils, is a mess and it is the young who will have to pay excessively for their own health, education and social security. The young also face uncertainty concerning global peace, prosperity and security. It is the young who seem to be destined to inherit a number of significant environmental problems and face a global mental-health epidemic. Yet, it is the same generation being infantilised by being told they need to focus better and learn to cope with the stresses of a world they did not create. Alongside socio-economic and familial pressures placed on early development, many of the 'wounds' mindfulness is well-placed to alleviate actually originate from schooling, hence the coupling of education 'and' mindfulness cannot be a serious contender for alleviation of suffering if one half of the equation is a significant cause.

The surge in advocacy of mindfulness is much like an apology from neoliberalism, an intervention to help people cope with the contemporary 
pressures of globalisation, characterised by increased competition for scarce resources that are controlled by financial elites and high-performers. Education is of course regarded as key to these processes in that it should educate a workforce to the degree that it participates efficiently in such a system but does not question it (Gatto 2017). It is easy to assume that schools perform an unquestionably positive function in societies. Pinker (2018) argues that education can be seen as part of an enlightenment project, where societal structures, even those regarded as hierarchical and dominant, are the very same forces that have reduced chaos and created fertile grounds for human flourishing. Whilst there are examples of educational approaches that challenge and disrupt hegemony (e.g. Freire 2014), education's positive function cannot be assumed. For classical-thinkers such as Bourdieu (2010), the school is the most systematic reproducer of social-class through cultural-capital. For Gatto (2017), schooling is the most effective technique for teaching conformity and state dependency. And for Harber (2004), schools are more analogous with prisons and exponents of systemic violence. They regulate attendance, movement, attention and conduct. For these theorists, there are dire consequences for those who contest or are excluded from education. Hence, mindfulness within such structures cannot be about enlightenment but adjustment to these structures of oppression. As Jiddu Krishnamurti is often quoted as saying, "it is not a measure of health to be well-adjusted to a profoundly sick society". If mindfulness happens to result in greater awareness, without support or opportunity for agency, it could have troubling ethical issues, discussed in the next section.

Echoing Hyland (2016), there is something 'oxymoronic' about mindfulness in education. Mindfulness emphasises a state-of-being, or deepened-awareness, which is generally characterised as non-striving (Kabat-Zinn 2013a). This is at odds with the typical school, which moves attention through neatly-parcelled segments of activity (lessons), with a focus on learning cognitive forms of apriori knowledge and the goading of students towards increasingly narrow measurements of performance. As Watts (2018) elucidates, many human-beings act as if their life is a journey and are rarely still or present-moment focused, they are moving towards the end of the lesson, the end of the day, the end of the academic year, the next milestone, university, job, the day when they have 
more money, then retirement, when they might finally be able to do something they love but probably have little energy. Along the way, they may have children who will in all likelihood repeat the same patterns. Within much mindfulness literature, there is the notion of being on auto-pilot. Segal et al (2013) ask us to question ourselves whether we have ever got to a destination without being able to recall anything about the journey? This is positioned as a means of cheating oneself out of life as moment-to-moment experience is overlooked and notsavoured. Schooling is guilty of a similar offence, emphasising continual goal orientation though Ergas (2015) suggests it is the consequences of striving in education that mindfulness can offset.

It is though difficult to reconcile mindfulness as promoting a state of 'being' in schools when a school career, as a component of a broader economic career, is beset by incessant doing and striving. Schooling represents a location at the intersection of bigger issues and debates about individual and collective potential. Many still naively regard a school as being a haven, outside of sociopolitical trends and forces and thus see interventions in schools as preparing people for the world. However, education is not apart from suffering produced by neoliberalism but a perpetrator of such. Most of those who succeed in such systems do not question schooling and hence go on to perpetuate and reproduce it, which is the antithesis of mindfulness. This is why Zajonc (2008) indicates that a duty of increased awareness is peaceful resistance to oppressive structures. Enabling students to do this is of course a considerable ethical dilemma and challenge.

\section{The ethics of mindfulness in education}

Whether mindfulness is implemented in education deeply or superficially it has the potential to release repressed and traumatic material (Farias \& Wikholm 2015, Lindahl et al 2017). This is part of its therapeutic, educative and transformative potential as long as experienced and qualified teachers are able 
to offer support. Whereas such material may surface anyway it is worth pondering the contribution of education itself to this propensity. From a critical standpoint, the neoliberal structures advocating mindfulness in education could be precisely the same structures responsible for and perpetuating suffering for many young-people (Reveley 2016). Yet, if mindfulness is successful, as it can be, in expanding consciousness of such a reality, young-people are potentially put in a perilous situation because they may become acutely aware of the conditioning and reproductive functions of schooling but not be ready for such profundity and/or possess little agency to do anything about it. This presents two possibilities, either keep quiet about this dis-contention and tolerate passage through education in a manner that can only be described as inauthentic or 'unmindful' - or contest the system and risk suffering its disciplinary, sometimes even exclusionary, wrath. There is a 'third-way', contesting the system whilst playing along though this requires extraordinary, but not uncommon, sophistication.

Many teachers may not be fully aware of, nor comfortable with, the extent to which they are reproducing a neoliberal agenda not least when they advocate or teach something as seemingly wholesome as mindfulness. A genuinely mindful education profession, savvy to the collusion of mindfulness with such an oppressive agenda would surely call for a return to more humanistic models of education that are focused on holistic development and a form of pedagogy which is more inquisitive than didactic. Authors such as Berila (2016) and Rendon (2009) remind us of both the necessity and challenge of integrating mindfulness with pedagogy for wholeness and social justice. Do we really want the same education system and its perpetuation of inequality and oppressions ten, twenty years from now? If not, there is a dire need to revaluate the nature and purpose of education and assure the place of anti-oppressive pedagogy in schools.

Any school wishing to implement mindfulness authentically has to ask searching questions. Is the emphasis going to be on fostering focus and stressmanagement as a means of enhancing educational performance before taking 
such attributes into the workplace - and maintaining the status quo? Or do such schools connect with the roots of mindfulness and see it as a vehicle for selfknowledge, integrity and ethical agency (Zajonc 2008) and as a means to creating a more sane and peaceful world (Tolle 2009)? The former emphasis slots in relatively easily into existing school structures. The second option requires schools to ask fundamental questions about policy, systems, pedagogic practice and the quality and function of inter-personal relationships. Each of these aspects will be briefly discussed in the final sections of this article, accompanied by some assertions about how to begin to resolve these difficulties.

\section{Reframing Mindfulness as Education, rather than a Psychological Intervention}

The instrumental application of mindfulness within educational and health settings commonly defines mindfulness as the awareness that arises from deliberately paying attention to the present-moment and doing so nonjudgementally (Kabat-Zinn 2013a, 2017). Many, including Hyland (2016) critique the widespread application of mindfulness as correlating with a reductionist approach of its meaning, resulting in less potential for deeper insight. This is a direct consequence of mindfulness being positioned as an 'intervention' with instrumental ends that can be mobilised in multiple settings, requiring the identification of measurable outcomes so courses and training can be standardised for comparability. The process of commodification necessitates breaking the phenomenon into smaller constituents as is the case with measures such as the 'Five-facets of Mindfulness' scale (Baer 2013). Issues concerning narrow definition and reductionism will be examined first and in more detail before constructing the basis of an argument for more holistic and embodied education. Given the scope of this article, we can only begin to indicate what such an approach may look like. We suggest scrutiny of pedagogy and relationships in schools as a starting point and begin to discuss what these elements would look like if they were informed by greater awareness. 


\section{Engaging with deeper definitions of mindfulness}

Mindfulness, like other qualities (e.g. love), has an ineffability that inevitably makes it difficult to define and measure, especially when transferred from one cultural-historical context to another (Nelson 2012). If mindfulness is not welldefined, as is the case, any attempt to reduce and measure it will be problematic. Although many courses draw on Kabat-Zinn's legacy in emphasising present-moment awareness and non-judgement even Kabat-Zinn (2017) realises that such an emphasis can be both limited and misunderstood. It may be self-evident that it is simply not possible to be anywhere other than in the present-moment so what is really being emphasised here concerns the sensibility brought to experience. Whereas a cultivation of concentration may be a necessary early step whilst developing a meditative mind, a superficial emphasis on this facet alone leads to a simplification that undoubtedly gives mindfulness its attractiveness to educational policymakers. Who would not want students better able to concentrate? However, original definitions of mindfulness are much deeper.

Drawing on others, Hyland (2016) argues that if we define mindfulness as maintaining present-moment awareness it serves instrumental goals such as enhancing focus and appreciating one's current material conditions. However, the word 'sati' (Pali for mindfulness), or the later concept from Sanskrit 'smrti' (meaning remembrance or recollection) is much wider and dynamic (Bodhi 2013, Brazier 2014, Dreyfus 2013, Peacock 2014). It places greater emphasis on personal transformation through enhanced self-knowledge, clarity and selfinquiry as well as re-orientation to the world through in-depth awareness as a vehicle for alleviating our own suffering and that of others. Neither term is solely about mindsets but also how to live. We will return to these important definitional issues shortly but first let us also consider the oft-cited notion of non-judgement, which can also be misleading. Practitioners of mindfulness tend to emphasise being non-judgemental but what this aspect actually refers to is the process of being kind to oneself, especially if practices prove difficult. KabatZinn's (2017) principle intention was to foster an attitude of compassion towards 
oneself, where a practitioner does not berate him/her-self for inevitable loss of concentration, mind-wandering or negative self-talk during or after a practice. It does not mean that evaluation of experience will not take place. In fact, discernment as a form of judgement or evaluation, built upon awareness, lies at the heart of mindfulness practice. Such skills differentiate 'formal' and 'nonformal practices' (e.g. playing sport mindfully), the former is not only more rigorous but contains analytical and evaluative tools for self-inquiry (Goleman 1988, Spira 2017), currently lacking in MBIs.

Synthesising remembrance and discernment, original conceptions of mindfulness are about bringing an object into focus for meditative contemplation (Dreyfus 2013). This could be an object from the past, pleasant or painful, which is why acceptance and curiosity are also lauded traits of mindfulness. This object is put under the spotlight of attention for scrutiny (cognitively, affectively and through body-awareness). In doing so, the act of mindfulness is also an act of recollection, of remembering all that has occurred to bring this object into its current form and the realisation that the object is also transitory and impermanent.

Going deeper still, Adyashanti (2010) refers to the process of 'enlightenment' itself as an act of remembrance. This pertains to the realisation that all objects are both eternal in their essence as matter and energy cannot be destroyed only transformed. Adyashanti does not see this as a straight-forward learning process, in fact he states it is often destructive because it necessitates the reformulation of world-view and sense-of-self, after a process of peeling back and clearing one's sight. In a similar vein, writers like Katie (2002), Spira (2017) and Tolle (2009) regard mindfulness and enlightenment, though they use a different vocabulary, as a process of ego-disidentification, meaning learning to observe one's experience, including thinking, which is often regarded as incessant and dysfunctional. Engagement with objects brought into mindfulness practices also includes recognising internal states with an emphasis on cultivating the wholesome and relinquishing the unwholesome (Hyland 2016). Such realisations are quite a contrast to learning to concentrate better yet are an educational entitlement of the highest-order (Zajonc 2008). 
The risk of instrumental applications of mindfulness (or poor teaching of the practices) is the potentiality of students to misperceive non-judgement as a mantra for aversion to any form of critical-thinking and if this happens it is counter-educational. It also infantilises participants, placing limits on the depth of their inquiry. When discernment is present, deep-learning, healing and transformation can take place. Similarly, an object could perceivably be brought from a potential future for inspection too. One is still in the present-moment but this is a type of practice both more dynamic and extensive than present-moment awareness by itself.

Learning skills that aid concentration and well-being are welcome within the current education system but the educational community need to recognise that the potential of mindfulness extends far beyond such limited objectives and the implications are profound. Rather than seeing mindfulness as a form of psychological-intervention, these practices need to be considered educational in nature, intended for radical knowledge-seeking about the nature of reality and personal experience. As Farias \& Wikholm's (2015, p.144) critique of MBIs in general remind us:

Meditation wasn't developed so we could lead less stressful lives or improve our wellbeing. Its primary purpose was much more radical - to rupture your idea of who you are; to shake to the core your sense of self so that you realize there is 'nothing there'. But that's not how we see meditation courses promoted in the West. Here, meditation has been revamped as a natural pill that will quieten your mind and make you happier.

Deeper definitions of mindfulness radically shift the agency of the sitter from one of passive acceptance to a situation where necessary lessons can be gleaned from the past and a range of more expansive and agentic possibilities for the future identified. This is quite a significant departure from accepting existing structures that impinge on agency. Becoming well-practiced in the liberating skill of being able to watch one's own thoughts including the mind's largely unhelpful rumination and self-chatter is a key part of the process. Tolle (2009) argues we should come to see our minds as useful tools that can be picked up and put down and not as representations of ourselves. Tolle's emphasis on ego-dis- 
identification has much greater political edge as once liberated, one's awareness includes the understanding of how culture (including schooling) construct and constrain the individual. This level of inquiry is largely absent from current MBIs and certainly in educational settings but has radical epistemological potential. Sincerity to the roots and original purpose of mindful living require that its principles permeate the whole of education and are not constrained to a small number of lessons about concentration and well-being.

\section{The need for teachers to embody mindfulness as a way of being in education}

Although students engaged with mindfulness are experiencing something quite different to a conventional curriculum, even if for brief periods of time, in order for the potential of mindfulness in education to be fully realised it needs to be part of a broader and ongoing debate about the nature and purpose of education (Ergas 2018a, Palmer 1998, Langer 2003, O'Reilly 1998, Rogers and Freiberg 1994), which can only be introduced here. This is timely, as education remains locked within industrial and medical models (Robinson 2017), predicated on an objectified external world that is looking increasingly shaky, particularly if education were to embrace contemporary developments about the nature of reality emerging in scientific debate (e.g. Lanza 2009, Sheldrake 2012). Mindfulness permeating rather than being seen as an 'intervention' in education has the potential to both catalyse a 'contemplative turn' (Eppert 2013) and rechampion the longstanding case for holistic development and emphasis on human flourishing, which has a long and credible heritage (John Dewey, Abraham Maslow and Carl Rogers being noteworthy).

Mindfulness challenges traditional pedagogic approaches as the type of learning that can take place may not be known in advance and the timing of any insights are also unpredictable (Ergas 2018a). The performativist machinery present in contemporary schooling privileges forms of knowledge that can be predicted in advance and easily-measured. Such an agenda remains a great obstacle to more nuanced forms of education. Why must we always teach as though knowledge is 
a-priori, separating the knowledge from the knower (Thompson 2017), particularly when the philosophical basis of much teaching draws upon ancient maxims such as the 'know-thyself' tradition?

At the heart of deeper and more authentic applications of mindfulness is the necessity of embodiment as a pedagogic practice. This has implications at multiple levels. On one level any taught material in mindfulness needs to encourage deeper awareness of the whole body and not just the mind. For example, one can read endless books about meditation yet without direct practical experience, one cannot begin to comprehend it profoundly nor integrate it fully into one's life. Such intimate understanding can only be garnered through forms of experiential learning, emphasising learning how to be reflexive, a skill that is not necessarily natural and needs to be guided or taught (Gelter 2003).

For maximum benefit, mindfulness as a way-of-being and form of emotional learning needs to be embodied in a teacher's daily educational practice and not just in the lessons when mindfulness is taught, as well as embedded within the school's systems and relationships (McLaughlin 2008). Embodiment of both content and process raises questions about the nature of pedagogy in schools. So what might this begin to look like in practice? Mindfulness does not sit easily with materialist, objectivist and performative pedagogies with didactic models of teaching. Rather, mindfulness will be more synergistic with pedagogic approaches that are more contemplative, dialectical and investigative (Eppert 2013, Ergas 2017, 2018a). Ergas (2018a) elaborates, describing approaches that afford students opportunities to i) turn inward, becoming aware of being aware, experiencing experience as means to deeper self-knowledge, ii) engage with time differently by being radically present, unrushed and non-striving, and iii) cultivate awareness differently by bringing the attributes of curiosity, compassion and discernment to experience.

Such pedagogic approaches are 'integral' and entirely consistent with a version of mindfulness that bridges rather than disconnects science and spirituality (Sheldrake 2017), which privileges direct experience/observation, personalinquiry and ethics as a means of integrating insights into real life. The re- 
emphasising of experience and investigation inherent in contemplative pedagogy shifts the purpose of education to greater alignment with the notion of 'eudemonia', or 'human flourishing', which sees education as a vehicle for human potential and enlightenment, something radically different to the current neoliberal emphasis on employability. In many ways this is a call to reclaim some of the traditions from earlier political movements within education that have placed emphasis on character, moral and affective education and a radical rejection of those few who say affective education has already gone too far or education should be academically or skills focused (e.g. Ecclestone \& Hayes 2009).

A contemplative pedagogy requires skilled teachers who value and embody the merits of stillness practices and reflexivity (Langer 2003, O'Reilly 1998, Thompson 2017). This is immediately challenging in itself. Lees (2012) refers to positive and negative silences in schools. Most students experience an abundance of negative silence, where quiet is perceived as an indicator of control and discipline, even used punitively. Positive silence refers to the occasions where stillness is encouraged for reflection, inquiry and growth. Clearly, any move towards a contemplative pedagogy needs to reclaim the notion and value of positive silence, reframing what silence means to youngpeople.

Ergas $(2017,2018 a)$ argues for deeper forms of contemplative inquiry in education that encourage discernment through body-awareness rather than practices that merely push thoughts away. This is a personal type of knowing where the body can speak the mind with greater reliability if only listened to. Ergas (2017) calls this attending in as well as out, so that internal and external sites of knowledge are both validated. Profundity arises from the fact that these experiences are not simply third-person inquiry but critical first-person inquiry (Katie 2002, Spira 2017). As these skills are neither easy, natural nor easy to guide, there needs to be an upskilling of teachers' skills in modelling such sensibilities and their desire to facilitate deeper self-knowledge. This is a monumental (but necessary) shift in pedagogy as it requires awareness to permeate the entire classroom experience including the potentially poisonous 
ways in which classrooms are currently managed. Mindful classroom relationships are introduced in the final section as a starting point for beginning to think about how mindfulness can be embodied into daily educational practice beyond direct teaching.

\section{Mindful relationships and classroom management}

Although exceptions exist (e.g. the CARE project reported by Jennings et al 2013), many mindfulness products commercially available to schools have an instrumental emphasis. The three most popular UK training-providers (MiSP, YouthMindfulness, MindUP) focus their training on the provision of template lessons and guidance in how to teach these lessons. Although these trainingproviders only admit teachers to their programmes who have previously undertaken an in-depth mindfulness-based course and have a practice of their own already, an analysis of their course content indicates that there is less emphasis on what it means to be a mindful teacher or establish a mindful classroom or school. In fact, one provider makes it clear in a disclaimer that the course does not cover aspects of classroom management and it is assumed that teachers will be competent in this area already. This is quite an assumption as teaching meditation to a large class of young-people is likely to raise issues of order, particularly if students are required to attend and/or have attention difficulties. Contradictions will also be inherent because the entire discourse of behaviour management and related policy is dominated by behaviourism with its emphasis on manipulation of behaviour through extrinsic-motivation and punitive justice. To spell this out, the way teachers are trained to manage classrooms is utterly unmindful.

An analysis of one typical product available to schools (MiSP's paws.b curriculum) provides 6 hours' worth of template lessons with a focus on basic psychology/neurology, each lesson including a couple of practices lasting a few minutes. Yet, students spend approximately six hours at school every day. What is the most likely source of teaching about mindfulness - a one-off or perhaps annual six-hour course or how a teacher manages the classroom on a day-today basis and the implicit messages about education conveyed through everyday pedagogy? In the lead author's research, quite shocking contradictions between 
the content of mindfulness materials and classroom management have been observed (e.g. a student being reprimanded with the phrase "that was not very mindful"), sometimes in the very same or proximal lesson. Such paradoxes give students mixed-messages and can only further compartmentalise mindfulness as a concentration/well-being skill that students must learn and apply themselves, without much support on integration. These messages are potentially confusing. For one lesson a week, students may be told to remain calm and present, which is radically undermined if a teacher then demonstrates reactivity, automated responses and execution of arbitrary behavioural sanctions when classroom order is challenged.

Academics both supporting and critiquing the place of 'emotional education' in schools agree that such learning takes place through inter-personal relationships, i.e. by example. Although more isolated voices, critics such as Ecclestone and Hayes (2009) argue emotional education is both unnecessary and dangerous. Unnecessary because it is taught anyway through relationship, dangerous because it turns emotional performance into yet another category/competence to compare and judge young-people by and on this last point they raise an important consideration. On the other hand, advocates argue that the fact that emotional education is taught implicitly is even more reason to explicate its pedagogy via scrutiny of relationships, systems and processes (McLaughlin 2008) and mindfulness is one suitable approach for doing this (Hyland 2009). As Hyland (2016) later argues there is a need for a pedagogical fit between teaching mindfully and teaching mindfulness, best exemplified by teachers who embody the practice and have a practice of their own, who also exercise self-care and compassion (as reported in Jennings et al 2013). This demands an ethical and responsive way-of-being in the classroom, which raises the issue of discipline.

The word discipline is often misunderstood and misrepresented by educational policy, more commonly being associated with matters of order and control. The term comes from the Latin 'disciplina' and is more closely related to education itself. It also has connotations with fields of study and the related concept of discipleship, which similarly emphasise being a teacher worthy of being followed. As a means of beginning to identify how mindfulness can be brought to daily educational practice, the time is ripe to bring to the attention of the educational 
community the idea of 'mindful discipline', which is advocated here as a starting point for supporting and deepening students experience of mindfulness. This is a vision where the everyday melee of events is managed non-reactively, compassionately, with awareness, emotional mastery and an inquiry-based process. One of the few authors to begin to apply ideas from mindfulness to relationship management with young-people are Siegel and Bryson (2016), with their concept of 'no-drama discipline'. They argue that embracing the authentic meaning of discipline requires teachers to identify the educative opportunity present in challenging circumstances and respond rather than react instead of pushing difficult material away. Mindful discipline may be an extremely effective way of negating the punitive and performative turn so prevalent in education by embodying mindfulness and deeper inquiry into the very heart of daily classroom practice. Such endeavour reclaims mindfulness as being deeply connected to the biggest and most timeless educational project of all - how to lead an ethical and fulfilling life that minimises the suffering of self and others.

School personnel perhaps fear going inward and what introspection may identify as most educators do not currently have the skills readily available to help people with this kind of process, nor the agency to deal with some of the implications of increased awareness, as previously discussed. Both young-people and teachers in schools generally don't feel they have the agency to change the educational system. But one of the potentially transformative elements of mindfulness practice is of course an awareness that they, teachers and students and not others, are the educational system.

\section{Conclusion}

Following Hyland (2016), this article further ratifies the need to engage with, deepen and clarify a number of conceptual, methodological and implementational issues. It has argued that it is necessary to deepen the definition of mindfulness used within education in order that its full potential for expanded consciousness and ethical living be realised. The socio-political nature of schools is currently under-estimated or overlooked. Mindfulness in education is no panacea for alleviation of suffering if education itself is toxic. In fact, the oxymoronic nature of mindfulness in education leaves enhanced awareness in a 
peculiar, potentially unethical, position, if participants become aware of an oppressive system but have limited agency to do much about it. In such a context, mindfulness is like adding lemon juice to poison. To begin to resolve this contradiction, mindfulness needs the support of a more contemplative pedagogy within and across education, which also permeates ways of being and ways of interrelating. Hence, as argued here there is an urgent need for the embodiment of mindfulness to be integrated with daily classroom pedagogy and management. Further research is needed to fully articulate what this will look like though several writers (Ergas 2015, 2017, Jennings et al 2013 as examples) have begun to landscape the terrain and there is a longstanding tradition of humanistic education to draw upon too.

The perils of not attending to these issues are that mindfulness in education will retain an instrumental focus and thus serve as a tool enabling students to cope with an education system that is inherently unmindful, if not damaging, rather than learning contemplative practices leading to more ethical conduct and an agentic-identity where personal and social transformation may be possible. Mindfulness within an institutional culture thus needs to be embraced as a collective way-of-being rather than an individual way of coping. MBIs would hence be better focused on deeper self-knowledge, discernment, compassion and ethics, ultimately underlined by viewing mindfulness in schools as an educational initiative rather than a psychological-intervention, characterised by mindfulness as rather than in education, a point to be more fully developed in future writing.

\section{Disclosure Statement}

No potential conflicts of interest were reported by either author

\section{ORCID}

Edward Sellman: https://orcid.org/0000-0001-9124-5502

Gabriella Buttarazzi: https://orcid.org/0000-0001-9679-755X 


\section{References}

Adyashanti (2010) The End of Your World (London, Sounds True).

American Mindfulness Research Association (2017) Mindfulness Publications by Year, 1980-2016 (https://goamra.org/)

Baer, R. A. (2013) Measuring mindfulness. In J.M.G. Williams and J. Kabat-Zinn (Eds) Mindfulness: Diverse Perspectives on Its Meaning, Origins and Applications (Abingdon, Routledge), 241-261.

Berila, B. (2016) Integrating Mindfulness into Anti-Oppression Pedagogy: Social Justice in Higher Education (Abingdon, Routledge).

Bodhi, B. (2013) What does mindfulness really mean? A canonical perspective. In J.M.G. Williams and J. Kabat-Zinn (Eds) Mindfulness: Diverse Perspectives on Its Meaning, Origins and Applications (Abingdon, Routledge), 19-39.

Bourdieu, P. (2010) Distinction (Abingdon, Routledge).

Brazier, C. (2014) 'Beyond Mindfulness: An Other-centred Paradigm' in A. Bazzano, (Ed) After Mindfulness (London, Palgrave Macmillan), 23-36.

Chaskalson, M. \& Reitz, M. (2018) Mind Time: How 10 mindful minutes can enhance your work, health and happiness (London, Harper Thorsons).

Department of Health (DOH) (2011) No Health Without Mental Health (London, $\mathrm{DOH})$. 
Doty, J. R. (2016) Into the Magic Shop (London, Yellow Kite).

Dreyfus, G. (2013) Is mindfulness present-centred and non-judgemental? A discussion of the cognitive dimensions of mindfulness. In J.M.G. Williams and J. Kabat-Zinn (Eds) Mindfulness: Diverse Perspectives on Its Meaning, Origins and Applications (Abingdon, Routledge), 41-54.

Ecclestone, K., and Hayes, D. (2009) The Dangerous Rise of Therapeutic Education (Abingdon, Routledge).

Eppert, C. (2013) Awakening Education: Toward a Rich Tapestry of Mindful and Contemplative Engagement for Social/Environmental Transformation. In J. Lin, R. Oxford and S. Brantmeier (Eds.) Re-envisioning Higher Education (Charlotte, NC, Information Age Publishing) 337-352.

Ergas, O. (2015). The Deeper Teachings of Mindfulness-Based 'Interventions' as a Reconstruction of 'Education', Journal of Philosophy of Education, 49 (2), 203220. doi: https://doi.org/10.1111/1467-9752.12137

Ergas, O. (2017). Reclaiming ethics through "self": A conceptual model of teaching practice, Teaching and Teacher Education, 68 (1), 252-261. doi: https://doi.org/10.1016/j.tate.2017.09.013

Ergas, O. (2018a). A contemplative turn in education: charting a curricular pedagogical countermovement, Pedagogy, Culture \& Society, doi:https://doi.org/10.1080/14681366.2018.1465111

Ergas, O. (2018b). Reconstructing 'Education' through Mindful Attention: Three Approaches to Mindfulness in Education. Keynote presentation at the Mindfulness in Schools Project Conference: The Future of Mindfulness in Education. London, June 16, 2018.

Farias, M., \& Wikholm, C. (2015) The Buddha Pill: Can Meditation Change You? (London, Watkins Publishing).

Freire, P. (2014) Pedagogy of Hope (London, Bloomsbury). 
Gatto, J. T. (2017) Dumbing Us Down (Gabriola Island, Canada, New Society Publishers).

Gelter, H. (2003) Why is reflective thinking uncommon? Reflective Practice, 4 (3), 337-344. doi: 10.1080/1462394032000112237

Goleman, D. (1988) The Meditative Mind: The Varieties of Meditative Experience (Los Angeles, CA: Tarcher).

Harber, C. (2004) Schooling as Violence (Abingdon, Routledge).

Health and Safety Executive (2017) Work-related stress, depression or anxiety statistics in Great Britain in 2017. Available at:

http://www.hse.gov.uk/statistics/causdis/stress/stress.pdf [accessed 5 November 2018].

Hyland, T. (2009) Mindfulness and the Therapeutic Function of Education, Journal of Philosophy of Education, 43 (1), 119-131. doi:10.1111/j.14679752.2008.00668.x

Hyland, T. (2014) Mindfulness-based interventions and the affective domain of education, Educational Studies, 40 (3), 277-291.

doi:10.1080/03055698.2014.889596

Hyland, T. (2016) The Limits of Mindfulness: Emerging Issues for Education, British Journal of Educational Studies, 64 (1), 97-117, doi:

10.1080/00071005.2015.1051946

Jennings, P. A., Frank, J. L., Snowberg, K. E., Coccia, M. A., \& Greenberg, M. T. (2013). Improving classroom learning environments by Cultivating Awareness and Resilience in Education (CARE): Results of a randomized controlled trial. School Psychology Quarterly, 28(4), 374-390. doi:

http://dx.doi.org/10.1037/spq0000035 
Lindahl J.R., Fisher N.E., Cooper D.J., Rosen R.K., Britton W.B. (2017) The varieties of contemplative experience: A mixed-methods study of meditationrelated challenges in Western Buddhists. PLOS ONE, 12(5): e0176239. doi: https://doi.org/10.1371/journal.pone.0176239

Katie, B. (2002) Loving What Is (London, Rider).

Kabat-Zinn, J. (2013a) Full Catastrophe Living (New York, Piaktus).

Kabat-Zinn, J. (2013b) Some reflections on the origins of MBSR, skilful means, and the trouble with maps. In J.M.G. Williams and J. Kabat-Zinn (Eds) Mindfulness: Diverse Perspectives on Its Meaning, Origins and Applications (Abingdon, Routledge), 281-307.

Kabat-Zinn, J. (2017) Too Early to Tell: The Potential Impact and ChallengesEthical and Otherwise-Inherent in the Mainstreaming of Dharma in an Increasingly Dystopian World, Mindfulness, 8, 1125-1135. doi 10.1007/s12671017-0758-2.

Langer, E. (2003). A mindful education. Educational Psychologist, 28 (1), 43-50. doi: https://doi.org/10.1207/s15326985ep2801 4

Lanza, R. (2009) Biocentrism (Dallas, BenBella).

Lees, H. (2012) Silence in Schools (Stoke on Trent, Trentham Books).

Masters, R. A. (2010) Spiritual Bypassing: When Spirituality Disconnects Us from What Really Matters (Berkeley, CA, North Atlantic Books).

McLaughlin, C. (2008) Emotional well-being and its relationship to schools and classrooms: a critical reflection, British Journal of Guidance and Counselling, 36 (4): 353-366. doi: https://doi.org/10.1080/03069880802364486

NEF [New Economics Foundation] (2014) Wellbeing in Four Policy Areas: Report by the All Party Parliamentary Group on Wellbeing Economics (London, NEF). 
Nelson, D. (2012) Implementing Mindfulness: Practice as the Home of Understanding, Philosophical Inquiry in Education, 20(2), 4-14.

O'Reilly, M. R. (1998) Radical Presence: Teaching as Contemplative Practice, (Portsmouth, NH, Heinemann).

Palmer, P. (1998) The Courage to Teach: Exploring the Inner Landscape of a Teacher's Life (San Francisco, CA: Wiley Jossey-Bass).

Peacock, J. (2014) 'Sati or Mindfulness? Bridging the Divide' in A. Bazzano, (Ed.) After Mindfulness (London, Palgrave Macmillan), 3-22.

Pinker, S. (2018). Enlightenment Now: The Case for Reason, Science, Humanism and Progress (New York, NY, Penguin).

Rendon, L. I. (2009). Sentipensante (Sensing/Thinking) Pedagogy: Educating for Wholeness, Social Justice and Liberation (Sterling, VA, Stylus Publishing).

Reveley, J. (2016). Neoliberal meditations: How mindfulness training medicalizes education and responsibilizes young people, Policy Futures in Education, 14 (4), 497-511. doi: https://doi.org/10.1177/1478210316637972

Robinson, K. (2017) Out of Our Minds (London, Capstone).

Roeser, R. (2014). The Emergence of Mindfulness-Based Interventions in Educational Settings, Advances in Motivation and Achievement, 18, 379-419. doi: https://doi.org/10.1108/S0749-742320140000018010.

Rogers, C. and Freiburg, J. (1994) Freedom to Learn (London, Prentice Hall).

Safran, J. D. (2014) McMindfulness: the marketing of well-being, PsychologyToday (June 2014), 1-2.

Schonert-Reichl, K. A., Roeser, R. W. \& Maloney, J. E. (2016) Handbook of Mindfulness in Education: Integrating Theory and Research into Practice (New York, Springer). 
Segal, Z., Williams, M., \& Teasdale, J. (2013) Mindfulness-based Cognitive Therapy for Depression (New York, Guildford).

Sellman, E., Cremin, H. \& McCluskey (Eds.) (2014) Restorative Approaches in Schools (Abingdon, Routledge).

Sheldrake, R. (2012) The Science Delusion (London, Coronet).

Sheldrake, R. (2017) Science and Spiritual Practices (London, Coronet).

Siegel, D. J. (2018) Aware: The Science and Practice of Presence (Melbourne, Scribe).

Siegel, D. J. \& Bryson, T. P. (2015) No-Drama Discipline (Melbourne, Scribe).

Spira, R. (2017) The Nature of Consciousness, (Oxford, Sahaja).

Taylor, S. (2010) Waking From Sleep (London, Hay House).

Thompson, B. (2017) Teaching with Tenderness: Towards an Embodied Practice (Champaign, IL, University of Illinois Press).

Tolle, E. (2009) A New Earth (London, Penguin).

Watts, A. (2018) Out of Your Mind (London, Souvenir).

Weare, K. (2012) Evidence for the impact of mindfulness on children and young people. Available at: https://mindfulnessinschools.org/wpcontent/uploads/2013/02/MiSP-Research-Summary-2012.pdf [accessed 5 November 2018].

Zajonc, A. (2008) Meditation as Contemplative Inquiry: When Knowing Becomes Love (Great Barrington, MA, Lindisfarne Press).

Zenner, C., Herrnleben-Kurz, S., \& Walach, H. (2014) Mindfulness-based interventions in schools-a systematic review and meta-analysis, Frontiers in Psychology, 5, 1-20. doi:10.3389/fpsyg.2014.0060 
Acknowledgements:

We would like to thank Monica McLean, Karen Neil, Stephen Joseph and the reviewers for comments on previous drafts.

Correspondence:

Edward Sellman,

CRHF, School of Education,

Jubilee Campus, University of Nottingham,

Nottingham, UK.

Email: edward.sellman@nottingham.ac.uk 